$\mathrm{CD}^{+} \mathrm{T}$ cells (14). Furthermore, IFN- $\alpha / \beta$ modulates Th1 responses (15) and inhibits production of Th2 cytokines (16), some of which (e.g., IL-5, IL-13) are upregulated in the mucosa of patients with UC (17). Interestingly, recent studies suggest that IFN- $\alpha / \beta$ is able to induce regulatory T cells (18) and, moreover, intestinal $\mathrm{CD}^{+}$plasmacytoid dendritic cells producing IFN- $\alpha / \beta$ after $C p G$ ODN stimulation were shown to induce the differentiation of naive $\mathrm{T}$ cells to IL-10secreting T regulatory 1-like cells (19).

The protective effect of $\mathrm{CpG}$ ODNs seems to be independent of IL-10, as they ameliorate spontaneous colitis in IL-10-deficient mice (7). However, a key remaining question is whether IFN- $\alpha / \beta$ treatment is beneficial in T cell-dependent animal models of colitis such as the well-established adoptive $\mathrm{CD}^{+}$CD45RB ${ }^{\text {high }}$ transfer model (20). Such detailed characterization of the biological function of IFN- $\alpha / \beta$ in experimental animal models will undoubtedly be of great value for future clinical trials in IBD.

Address correspondence to: Markus F. Neurath, Laboratory of Immunology, First Medical Clinic, University of Mainz, Langenbeckstrasse 1, 55101 Mainz, Germany. Phone: 49-6131-172374; Fax: 49-6131-39175508; E-mail: neurath@1-med.klinik.uni-mainz.de.
1. Targan, S.R., et al. 1997. A short-term study of chimeric monoclonal antibody cA2 to tumor necrosis factor alpha for Crohn's disease. Crohn's Disease cA2 Study Group. N. Engl. J. Med. 337:1029-1035.

2. Mannon, P.J., et al. 2004. Anti-interleukin-12 antibody for active Crohn's disease. N. Engl. J. Med. 351:2069-2079.

3. Madsen, S.M., et al. 2001. An open-labeled, randomized study comparing systemic interferon-alpha$2 \mathrm{~A}$ and prednisolone enemas in the treatment of left-sided ulcerative colitis. Am. J. Gastroenterol. 96:1807-1815

4. Nikolaus, S., et al. 2003. Interferon beta-1a in ulcerative colitis: a placebo controlled, randomised, dose escalating study. Gut. 52:1286-1290.

5. Bogdan, C., Mattner, J., and Schleicher, U. 2004. The role of type I interferons in non-viral infections. Immunol. Rev. 202:33-48.

6. Katakura, K., et al. 2005. Toll-like receptor 9induced type 1 IFN protects mice from experimental colitis. J. Clin. Invest. 115:695-702. doi:10.1172/ JCI200522996.

7. Rachmilewitz, D., et al. 2002. Immunostimulatory DNA ameliorates experimental and spontaneous murine colitis. Gastroenterology. 122:1428-1441.

8. Obermeier, F., et al. 2003. Contrasting activity of cytosin-guanosin dinucleotide oligonucleotides in mice with experimental colitis. Clin. Exp. Immunol. 134:217-224.

9. Rachmilewitz, D., et al. 2004. Toll-like receptor 9 signaling mediates the anti-inflammatory effects of probiotics in murine experimental colitis. Gas troenterology. 126:520-528.

10. Obermeier, F., et al. 2002. CpG motifs of bacterial DNA exacerbate colitis of dextran sulfate sodiumtreated mice. Eur. J. Immunol. 32:2084-2092.

11. Atreya, R., et al. 2000. Blockade of interleukin 6 trans signaling suppresses T-cell resistance against apoptosis in chronic intestinal inflammation: evidence in crohn disease and experimental colitis in vivo. Nat. Med. 6:583-588.

12. Simpson, S.J., et al. 1998. T cell-mediated pathology in two models of experimental colitis depends predominantly on the interleukin 12/signal transducer and activator of transcription (Stat)-4 pathway, but is not conditional on interferon gamma expression by T cells. J. Exp. Med. 187:1225-1234.

13. Wirtz, S., and Neurath, M.F. 2000. Animal models of intestinal inflammation: new insights into the molecular pathogenesis and immunotherapy of inflammatory bowel disease. Int. J. Colorectal Dis. 15:144-160.

14. Aman, M.J., et al. 1996. Interferon-alpha stimulates production of interleukin-10 in activated CD4+ T cells and monocytes. Blood. 87:4731-4736.

15. Nguyen, K.B., et al. 2000. Interferon alpha/beta-mediated inhibition and promotion of interferon gamma: STAT1 resolves a paradox. Nat. Immunol. 1:70-76.

16. Kaser, A., Molnar, C., and Tilg, H. 1998. Differential regulation of interleukin 4 and interleukin 13 production by interferon alpha. Cytokine. 10:75-81.

17. Fuss, I.J., et al. 1996. Disparate CD4+ lamina propria (LP) lymphokine secretion profiles in inflammatory bowel disease. Crohn's disease LP cells manifest increased secretion of IFN-gamma, whereas ulcerative colitis LP cells manifest increased secretion of IL-5. J. Immunol. 157:1261-1270.

18. Levings, M.K., et al. 2001. IFN-alpha and IL-10 induce the differentiation of human type $1 \mathrm{~T}$ regulatory cells. J. Immunol. 166:5530-5539.

19. Bilsborough, J., George, T.C., Norment, A., and Viney, J.L. 2003. Mucosal CD8alpha+ DC, with a plasmacytoid phenotype, induce differentiation and support function of $\mathrm{T}$ cells with regulatory properties. Immunology. 108:481-492.

20. Powrie, F., Correa-Oliveira, R., Mauze, S., and Coffman, R.L. 1994. Regulatory interactions between CD45RBhigh and CD45RBlow CD4+ T cells are important for the balance between protective and pathogenic cell-mediated immunity. J. Exp. Med. 179:589-600.

\title{
Vascular remodeling and the kallikrein-kinin system
}

\author{
Oscar A. Carretero
}

Hypertension and Vascular Research Division, Henry Ford Hospital, Detroit, Michigan, USA.

\begin{abstract}
Remodeling of the arterial wall occurs mainly as a consequence of increased wall stress caused by hypertension. In this issue of the JCI, Azizi et al. report that in humans with a kallikrein gene polymorphism that lowers kallikrein activity, the brachial artery undergoes eutrophic inward remodeling in the absence of hypertension or other hemodynamic changes (see the related article beginning on page 780 ). It has also been reported that alterations of the kallikrein-kinin system are associated with formation of aortic aneurysms. Conversely, after vascular injury, kinins mediate the beneficial effect of angiotensin-converting enzyme inhibitors that prevent neointima formation. These findings raise the intriguing possibility that decreased kallikrein-kinin system activity may play an important role in the pathogenesis of vascular remodeling and disease, while increased activity may have a beneficial effect.
\end{abstract}

Conflict of interest: The author has declared that no conflict of interest exists.

Citation for this article: J. Clin. Invest. 115:588-591 (2005). doi:10.1172/JCI200524567.

\section{Kallikrein-kinin system, vascular expression, and release}

Kinins (bradykinin and lysyl-bradykinin) have been implicated in the regulation of renal function, blood flow, and blood pressure (1). The vasodilator, natriuretic, and diuretic effects of kinins are mediated by the release of autacoids such as eicosanoids, NO, and endotheliumderived hyperpolarizing factor. Kinins are released from kininogen by proteolytic enzymes known as kininogenases, the main kininogenases being plasma and tissue (glandular) kallikrein (hereafter referred to as kallikrein). Kinins are rapidly hydrolyzed by a group of peptidases known as kininases (Figure 1). In the blood, kinins circulate in the low picogram range (2-20 pg), a concentration 100 times lower than that needed to decrease blood pressure (2). Thus, if kinins participate in the regulation of blood flow, 


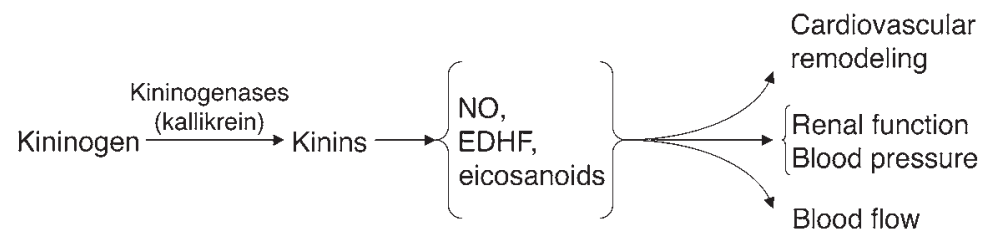

blood pressure, and renal function, they must act as autocrine hormones (at the site of release) or paracrine hormones (near the site of release) (3).

Kallikrein mRNA and protein are present in blood vessels, which indicates that kallikrein is synthesized in vascular tissue (4-6). Kallikrein is released from isolated arteries and into the perfusate of isolated rat hindquarters and kidneys (7-9). While the factors that control vascular kallikrein expression have not been studied in detail, arterial kallikrein is decreased in Goldblatt renovascular hypertensive rats (10). Conversely, in the acute phase of experimental mineralocorticoid/salt hypertension ( 2 weeks after administration of mineralocorticoid/salt is begun), arterial tissue kallikrein concentration and release are both increased. However, in the chronic phase (4-6 weeks) arterial kallikrein is decreased, while in the veins, tissue kallikrein is increased in both the acute and chronic phase (9). In humans and rats with mineralocorticoid/salt hypertension, renal kallikrein excretion is increased, while in essential hypertension and other types of hypertension,

\section{Figure 1}

Mechanism of kinin generation and effect of kinins via various intermediaries (NO, endothelium-derived hyperpolarizing factor [EDHF], and cyclooxygenase- and cytochrome P450-derived eicosanoids).

it is decreased (11). Thus expression of kallikrein in the vascular tissue may not necessarily parallel urinary kallikrein excretion.

\section{Kallikrein-kinin system, vascular remodeling, and disease}

In this issue of the JCI, Azizi et al. (12) report that subjects with a polymorphism of the human kallikrein gene $K L K$ $(\mathrm{R} 53 \mathrm{H})$ have lower urinary kallikrein excretion compared with that of control subjects (R53R). As a consequence of this polymorphism, the kallikrein
A

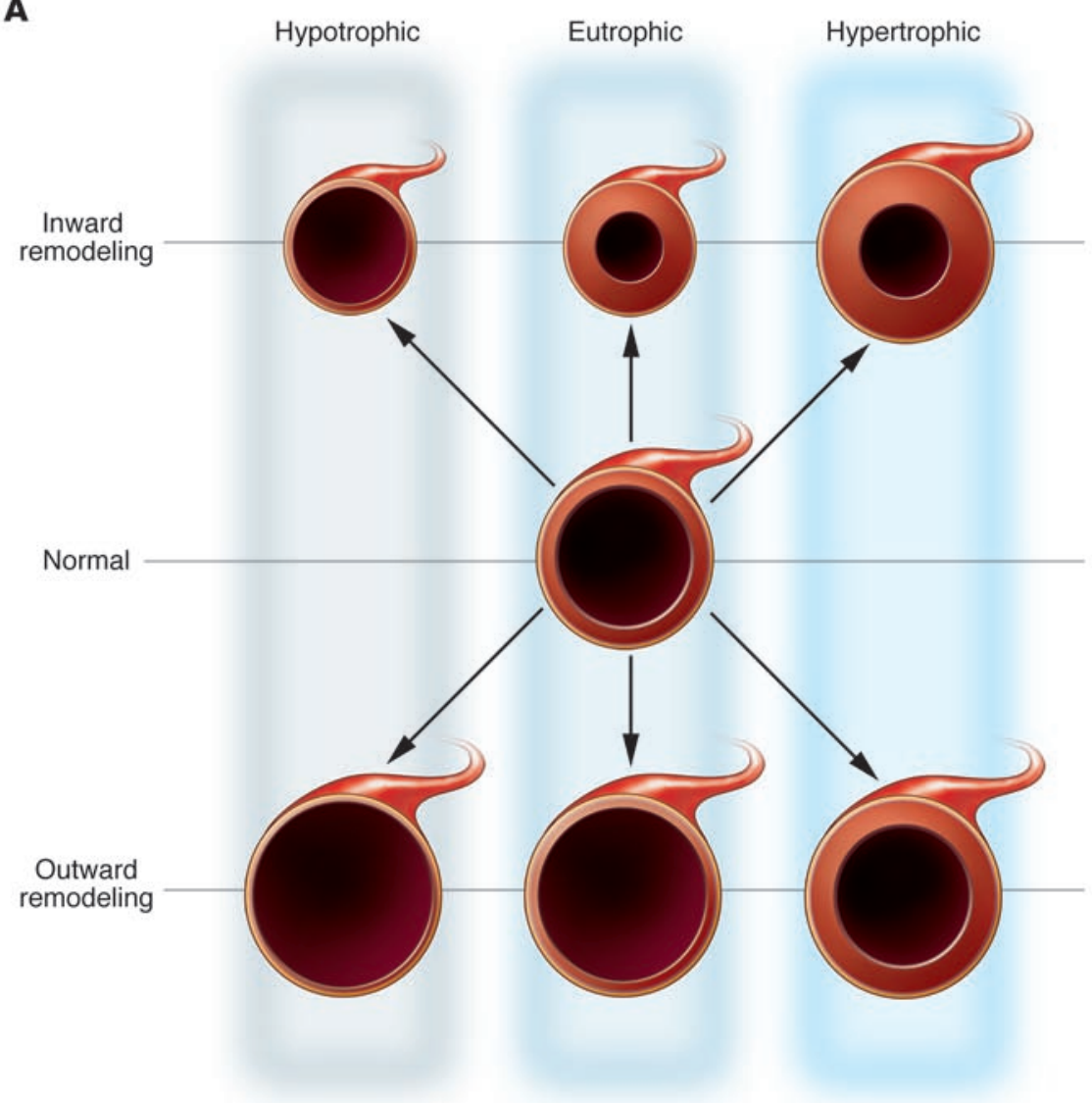

B

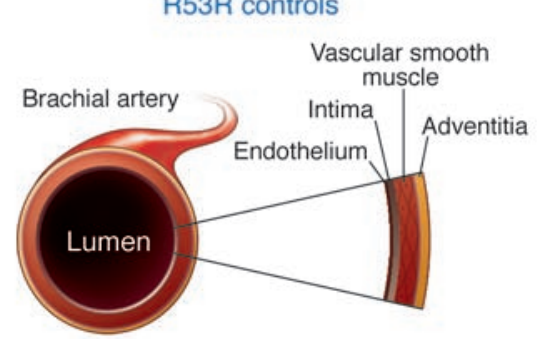

$\mathrm{R} 53 \mathrm{H}$ heterozygotes Inward eutrophic remodeling

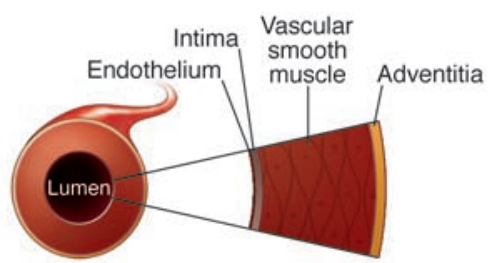

Decreased arterial diameter Decreased lumen Increased shear stress

Figure 2

Arterial remodeling. (A) Diagram showing the manner in which remodeling can modify the cross-sectional area of arteries. The vessel in the center represents a normal artery. Remodeling can be hypotrophic, represented by reduced cross-sectional area of the vessel wall (left); eutrophic, with no change in cross-sectional area (center); or hypertrophic, characterized by increased cross-sectional area (right). These forms of remodeling can be inward, showing decreased lumen diameter (top); or outward, with increased lumen diameter (bottom). Modified with permission from Hypertension (13). (B) Diagram of a normal arterial wall (left) and an arterial wall with eutrophic inward remodeling, showing the decrease in both lumen and external diameter of the artery with normal wall area (right). 
expressed has decreased enzymatic activity. Thus, in affected subjects, kallikrein activity should also be decreased in the arterial wall and other tissues, since the polymorphism alters enzymatic activity, not kallikrein expression. In individuals carrying the polymorphism, compared with control subjects, there is a decrease in the internal diameter of the brachial artery but no change in cross-sectional area, a process referred to as eutrophic inward remodeling (Figure 2) (for review, see Mulvany et al.; ref. 13). In these subjects, the arterial wall did not adapt to a chronic increase in shear stress. Azizi et al. indicate that $5-7 \%$ of normotensive Caucasian subjects will have the $\mathrm{R} 53 \mathrm{H}$ polymorphism and consequently will exhibit eutrophic inward remodeling of the brachial artery. Despite remodeling of the arterial wall and decreased urinary kallikrein enzymatic activity, the subjects had normal blood pressure; however, one of the criteria for inclusion in this study was normotension. Moreover, all of the subjects were young (18-35 years). As individuals with the polymorphism - both the heterozygous ( $\mathrm{R} 53 \mathrm{H})$ and the rare homozygous $(\mathrm{H} 53 \mathrm{H})$ form - grow older, it will be extremely interesting to observe whether they develop hypertension or other vascular diseases.

The authors recognize that the changes they observed in vascular remodeling could be caused by variations in another gene located at the same site as $K L K$, and this possibility cannot be ruled out. However, the assumption that the kallikreinkinin system may play an important role in vascular remodeling and development of vascular disease is also supported by a recent report indicating that kininogen deficiency is associated with aortic aneurysm formation (14). Both kininogen-deficient Brown Norway Katholiek rats (which have a spontaneous mutation in the kininogen gene) and normal Brown Norway rats (which have normal kininogen) are susceptible to development of lesions in the internal elastic lamina of the aorta; however, in that study, a higher proportion of kininogendeficient rats (50\%) developed aneurysms than those with normal kininogen (32\%). The aneurysms were associated with enhanced elastolysis, FasL- and caspase-3mediated apoptosis, induction of MMP-2 and MMP-3 proteolytic cascades, and downregulation of tissue inhibitor of matrix metalloproteinase- 4 protein
(TIMP-4). Kininogen deficiency was also associated with changes in plasma concentrations of various cytokines. We have reported $(15,16)$ that carotid neointima formation after endothelial injury was prevented by an angiotensin-converting enzyme or kininase II inhibitor and this effect was mediated by kinins and NO. Furthermore, inactivation of the tissue kallikrein gene in mice induced endothelial dysfunction but not arterial remodeling. However, in these mice, the septum and posterior wall are thinned and left ventricular mass is reduced, while the heart tends to dilate (17-19). Collectively, these studies suggest that the cardiovascular kallikrein-kinin system may play a role in arterial and cardiac remodeling and pathology. However, it is very intriguing that these forms of vascular remodeling have a different pathogenesis: (a) eutrophic inward remodeling of the brachial artery, which may be due to restructuring of vascular smooth muscle cells around a smaller lumen as a result of chronic vasoconstriction (20); (b) aortic aneurysms, which may be due to enhanced elastolysis and apoptosis; and (c) neointima formation, which may be due to myofibroblast and vascular smooth muscle cell proliferation and migration to the neointima. Thus, further studies are needed to understand the mechanism by which changes in vascular kallikrein-kinin system activity cause a heterogeneous alteration in the arterial wall and establish whether these changes lead to vascular diseases and hypertension.

\section{Role of the kallikrein-kinin system in sodium and water excretion}

Azizi et al. (12) also conclude that despite a $50 \%$ deficiency in urinary kallikrein activity in $\mathrm{R} 53 \mathrm{H}$-heterozygous individuals compared with control individuals (R53R), the kidney adapts to large variations in sodium and potassium intake. Although the subjects reach a sodium balance 7 days after being placed on either a low-sodium/high-potassium or high-sodium/low-potassium diet, this is not a very sensitive indicator of whether or not the renal kallikrein-kinin system plays an important role in the regulation of sodium and water excretion. We and others have produced evidence that the renal kallikrein-kinin system contributes to both acute and chronic regulation of water and sodium excretion as well as regulation of renal vascular resistance and medullary blood flow (21-23). For example, mice lacking kinin $\mathrm{B}_{2}$ receptors develop hypertension and increased renal vascular resistance after at least 6 weeks of a very high-sodium diet $\left(3.15 \% \mathrm{Na}^{+}\right.$in food plus $1 \%$ saline in drinking water) (24). It is beyond the scope of this commentary to discuss the possible role of the renal kallikrein-kinin system in the regulation of renal function (for a review, see ref. 1).

In conclusion, the interesting studies by Azizi et al. (12), reporting remodeling of the brachial artery in human subjects with a polymorphism of the kallikrein gene; Unger's group (14), reporting increased aneurysm formation in rats deficient in kininogen; and Meneton et al. (17), reporting decreased flow-induced dilatation in kallikrein gene-deficient mice, as well as previous publications regarding vascular kallikrein alterations in hypertension $(9,10)$, raise the possibility that the genetic association between the genotype $\mathrm{R} 53 \mathrm{H}$ and inward remodeling of the brachial artery is causally linked to kallikrein deficiency. These findings also raise the possibility that alterations of the arterial kallikrein-kinin system may play an important role in the pathogenesis of vascular diseases.

Address correspondence to: Oscar A. Carretero, Hypertension and Vascular Research Division, Henry Ford Hospital, 2799 West Grand Boulevard, Detroit, Michigan 48202, USA. Phone: (313) 916-2103; Fax: (313) 916-1479; E-mail: ocarret1@hfhs.org.

1. Carretero, O.A., Yang, X.-P., and Rhaleb, N.-E. 2005. The kallikrein-kinin system as a regulator of cardiovascular and renal function. In Hypertension: a companion to Brenner and Rector's The kidney. S. Oparil and M. Weber, editors. Elsevier. Philadelphia, Pennsylvania, USA. 203-218.

2. Salgado, M.C.O., Rabito, S.F., and Carretero, O.A. 1986. Blood kinin in one-kidney, one clip hypertensive rats. Hypertension. 8(Suppl. I):I110-I113.

3. Carretero, O.A., and Scicli,A.G. 1988. Kinins paracrine hormone. Kidney Int. 34(Suppl. 26):S52-S59.

4. Nolly, H., Scicli, A.G., Scicli, G., and Carretero, O.A. 1985. Characterization of a kininogenase from rat vascular tissue resembling tissue kallikrein. Circ. Res. 56:816-821.

5. Nolly, H., et al. 1986. Kininogenase from rat vascular tissue. Adv. Exp. Med. Biol. 198A:11-17.

6. Saed, G.M., Carretero, O.A., MacDonald, R.J., and Scicli, A.G. 1990. Kallikrein messenger RNA in rat arteries and veins. Circ. Res. 67:510-516.

7. Nolly, H., Carretero, O.A., and Scicli, A.G. 1993. Kallikrein release by vascular tissue. Am. J. Physiol. 265:H1209-H1214.

8. Vio, C.P., et al. 1983. Renal kallikrein in venous effluent of filtering and non-filtering isolated kidneys. Adv. Exp. Med. Biol. 156B:897-905. 
9. Nolly, H., Carretero, O.A., Lama, M.C., Miatello, R., and Scicli, A.G. 1994. Vascular kallikrein in deoxycorticosterone acetate-salt hypertensive rats. Hypertension. 23(Suppl. I):I185-I188.

10. Nolly, H., Carretero, O.A., Scicli, G., Madeddu, P., and Scicli, A.G. 1990. A kallikrein-like enzyme in blood vessels of one-kidney, one-clip hypertensive rats. Hypertension. 16:436-440.

11. Carretero, O.A., and Scicli, A.G. 1995. The kallikrein-kinin system as a regulator of cardiovascular and renal function. In Hypertension: physiology, diagnosis, and management. J.H. Laragh and B.M. Brenner, editors. Raven Press. New York, New York, USA. 983-999.

12. Azizi, M., et al. 2005. Arterial and renal consequences of partial genetic deficiency in tissue kallikrein activity in humans. J. Clin. Invest. 115:780-787. doi:10.1172/JCI200523669.

13. Mulvany, M.J., et al. 1996. Vascular remodeling. Hypertension. 28:505-506.
14. Kaschina, E., et al. 2004. Genetic kininogen deficiency contributes to aortic aneurysm formation but not to atherosclerosis. Physiol. Genomics. 19:41-49.

15. Farhy, R.D., Carretero, O.A., Ho, K.-L., and Scicli, A.G. 1993. Role of kinins and nitric oxide in the effects of angiotensin converting enzyme inhibitors on neointima formation. Circ. Res. 72:1202-1210.

16. Ellenby, M.I., Ernst, C.B., Carretero, O.A., and Scicli, A.G. 1996. Role of nitric oxide in the effect of blood flow on neointima formation. J. Vasc. Surg. 23:314-322.

17. Meneton, P., et al. 2001. Cardiovascular abnormalities with normal blood pressure in tissue kallikrein-deficient mice. Proc. Natl. Acad. Sci. U. S. A. 98:2634-2639.

18. Bergaya, S., et al. 2001. Decreased flow-dependent dilation in carotid arteries of tissue kallikreinknockout mice. Circ. Res. 88:593-599.

19. Bergaya, S., Matrougui, K., Meneton, P., Henrion, D., and Boulanger, C.M. 2004. Role of tissue kallikrein in response to flow in mouse resistance arteries. J. Hypertens. 22:745-750.

20. Bakker, E.N.T.P., et al. 2002. Inward remodeling follows chronic vasoconstriction in isolated resistance arteries. J. Vasc. Res. 39:12-20.

21. Tomiyama, H., Scicli, A.G., Scicli, G.M., and Carretero, O.A. 1990. Renal effects of Fab fragments of kinin antibodies on deoxycorticosterone acetate-salt-treated rats. Hypertension. 15:761-766.

22. Fenoy, F.J., Scicli, A.G., Carretero, O., and Roman, R.J. 1991. Effect of an angiotensin II and a kinin receptor antagonist on the renal hemodynamic response to captopril. Hypertension. 17:1038-1044.

23. Saitoh, S., Scicli, A.G., Peterson, E., and Carretero, O.A. 1995. Effect of inhibiting renal kallikrein on prostaglandin $\mathrm{E}_{2}$, water, and sodium excretion. Hypertension. 25:1008-1013.

24. Alfie, M.E., Sigmon, D.H., Pomposiello, S.I., and Carretero, O.A. 1997. Effect of high salt intake in mutant mice lacking bradykinin- $\mathrm{B}_{2}$ receptors. Hypertension. 29:483-487.

\title{
Licking latency with licorice
}

\author{
Jeffrey I. Cohen
}

\author{
Medical Virology Section, Laboratory of Clinical Infectious Diseases, NIH, Bethesda, Maryland, USA.
}

\begin{abstract}
Numerous viruses cause latent infections in humans, and reactivation often results in pain and suffering. While vaccines for several of these viruses are available or currently being studied in clinical trials, and antiviral therapies have been successful in preventing or treating active infection, therapy to eradicate latent infection has lagged behind. A new study reported in this issue of the JCI shows that treatment of cells latently infected with Kaposi sarcoma-associated herpesvirus (KSHV) with glycyrrhizic acid, a component of licorice, reduces synthesis of a viral latency protein and induces apoptosis of infected cells (see the related article beginning on page 642). This finding suggests a novel way to interrupt latency.
\end{abstract}

Licorice, derived from the root of Glycyrrbiza glabra, has been used for more than 4 millennia as a flavoring agent in foods, beverages, and tobacco (1). Licorice is also used as an alternative medicine for the treatment of gastric and duodenal ulcers, sore throat, bronchitis, cough, arthritis, adrenal insufficiency, and allergic diseases. The licorice root contains numerous compounds, including glycyrrhizic acid (GA). It is estimated that in the United States, $3.3 \mathrm{mg}$ of GA is consumed per person daily. GA inhibits the replication of several viruses in vitro including herpesviruses, HIV, and the SARS coronavirus. When taken orally, GA is hydrolyzed to glycyrrhetic

Nonstandard abbreviations used: EBV, Epstein-Barr virus; GA, glycyrrhizic acid; KSHV, Kaposi sarcomaassociated herpesvirus; IL-6R, IL-6 receptor; LANA-1, latency-associated nuclear antigen 1 ; PEL, primary effusion lymphoma; Rb, retinoblastoma tumor-suppressor protein; v-cyclin, KSHV cyclin protein; $v$ FLIP, viral FLICE-inhibitory protein; vIL-6, viral IL-6.

Conflict of interest: The author has declared that no conflict of interest exists.

Citation for this article: J. Clin. Invest. 115:591-593 (2005). doi:10.1172/JCI200524507. acid by bacteria in the gastrointestinal tract before GA can be absorbed. Therefore, in Asia, where GA is used for the treatment of chronic hepatitis $\mathrm{B}$ or $\mathrm{C}$ infection, the drug is infused intravenously to achieve the appropriate serum levels.

In this issue of the JCI, Curreli et al. (2) show that GA induces apoptosis of primary effusion lymphoma (PEL) cells that are transformed by Kaposi sarcoma-associated herpesvirus (KSHV). KSHV is the etiologic agent of Kaposi sarcoma, and the virus is present in lesions from patients with multicentric Castleman disease and PEL. The latter presents as a malignant effusion located in the pleural, peritoneal, or pericardial space; tumor cells can also infiltrate the adjacent tissues. The virus is latent in PEL cells, which express a very limited set of viral proteins. The median survival time after diagnosis for patients with PEL is 6 to 12 months with chemotherapy and radiation therapy; thus, newer approaches to therapy are needed.

Curreli et al. (2) found that GA downregulates synthesis of the KSHV latency- associated nuclear antigen 1 (LANA-1) (Figure 1). LANA-1 is expressed in all KSHV-infected cells, including PEL cells. This protein allows the viral genome to be maintained as an episome in latently infected cells. LANA-1 binds to p53, inhibiting p53-mediated apoptosis, and interacts with the retinoblastoma tumor-suppressor protein $(\mathrm{Rb})$, which may prevent Rb-mediated cell cycle arrest. Curreli et al. found that downregulation of LANA-1 by GA was associated with an alteration in the mitochondrial membrane potential with translocation of apoptosis-inducing factor to the nucleus, DNA fragmentation, and apoptosis (2). In addition, cells treated with GA showed higher levels of phosphorylated (active) p53, which resulted in cell cycle arrest at the G1 checkpoint. GA upregulated expression of the KSHV cyclin protein ( $\mathrm{v}$-cyclin) but did not affect expression of the viral FLICEinhibitory protein (vFLIP). V-cyclin binds to and activates cyclin-dependent kinase 6 , which results in phosphorylation and inactivation of p53 and Rb. The increased level of v-cyclin in PEL cells treated with GA might also contribute to cell death, since overproduction of the protein has been reported to induce apoptosis.

\section{Additional molecular approaches to killing latent KSHV-infected PEL cells}

Other approaches have been considered for the treatment of PEL, based on KSHV gene expression in these tumors. Tumor cells 